\title{
Plasmonic Imaging in Thin Layer of PVP Contains Silver Nanowires
}

\author{
Nizar Shnan $^{\text {a,b }}$, Ahmed Kodeary ${ }^{a, b}$, Saddam Haddawi ${ }^{a, b}$, Neda Roostaei ${ }^{a}$, Seyedeh Mehri \\ Hamidi $^{\text {a }}$ ** \\ ${ }^{a}$ Magneto-Plasmonic Lab., Laser and Plasma Research Institute, Shahid Beheshti University, \\ Tehran, Iran. \\ ${ }^{b}$ Department of Laser Physics, College of Science for Women, University of Babylon, Babylon, \\ Iraq.
}

*Corresponding author: m_hamidi@sbu.ac.ir

Regular paper: Received: May. 22, 2020, Revised: Sep. 6, 2020, Accepted: Oct. 15, 2020, Available Online: Oct. 17,2020, DOI: 10.29252/ijop.14.2.109

\begin{abstract}
Silver nanowires are the favorable material in many applications based on their plasmonic double resonance in the visible region. In this paper, thin films of Poly-vinylpyrrolidone (PVP) doped with Silver nanowires (Ag NWs) in different concentrations have been prepared. The plasmonic imaging system using a high numerical aperture objective lens excite the Surface Plasmon in these structures. The hot spot results from reflected light intensity of surface plasmon resonance (SPR) proved that increasing of concentration of Silver nanowires yields to get better hot spot in plasmonic imaging systems by choosing the appropriate wavelength. These obtained results accompanying with third order nonlinear investigations show the ability of samples usage in thermoplasmonic applications.
\end{abstract}

KEYWORDS: Silver Nanowires, Surface Plasmon Resonance, PVP thin films, Nonlinear Refractive Index, Plasmonic Imaging, and Z-Scan Technique.

\section{I.INTRODUCTION}

Plasmonic imaging and collect data from the plasmonic hot spot is one of the main aims in this new born topic [1]. Plasmonic nanostructures proposed as new efficient heat source when illuminated by their correspondence resonance light source $[1,2]$ to use them in nanoscale control of temperature distribution [3], drug delivery [4], cancer photo thermal therapy, photo thermal imaging and many other useful applications. These applications need to the ability of measure the temperature distribution in enough area with high signal-to-noise ratio (SNR).

On the other hand, in these hotspots, the other optical properties like as nonlinear properties is so important due to the self-focusing effect in enhancing the temperature.

In this paper, we want to introduce new excitation method based on large numerical aperture (NA) lens and coupled charge camera to collect the plasmonic imaging from different samples with diverse concentrations of Ag NWs.

Until now, there are a lot of papers which focus on the study the optical properties of $\mathrm{Ag}$ NWs in polymer films [5] - [14], but the effect of self-focusing or de focusing onto the plasmonic hot spot by the aid of plasmonic imaging systems remains as an open question.

\section{Experimental Procedure}

\section{A. Materials}

The materials used in this work, the silver nanowire (>99\%) were purchased from SigmaAldrich, its length and width 1um, 100nm respectively. Poly vinyl pyrrolidone (PVP) $(\mathrm{Mw}=55000 \mathrm{~g} / \mathrm{mol})$ was purchased from Merck.

\section{B. Samples preparations}

The samples investigated in this studying are a mixture of Ag NWs with PVP polymer dissolved in deionized water using a magnetic stirrer. Our samples are prepared by adding the PVP films doped Ag NWs at five different compositional percentages $(2 \%, 4 \%, 8 \%, 12 \%$, 
and $16 \%$ ) and then stirred in an ultrasonic bath for about $15 \mathrm{~min}$, as shown in Fig. 1. This procedure according to the following steps: the first step of samples preparation is solving PVP in deionized water in rate $3 \mathrm{mg} / \mathrm{ml}$, the second step mixture the $\mathrm{Ag}$ NWs with deionized water in five different concentrations, the third step is mixture the PVP with Ag NWs in rate 50\%. The last step is preparing thin films layer by the spin coating method in condition $2000 \mathrm{rpm}$.



Fig. 1. Sample preparation steps.

\section{Z scan technique}

The nonlinear refractive index $\left(\mathrm{n}_{2}\right)$ of all the samples are measured by z-scan technique. We utilized the closed aperture $\mathrm{z}$-scan technique using a continuous wave $\mathrm{Nd}$ :YAG laser at $\lambda$ $=532 \mathrm{~nm}$ as the light source. A Gaussian beam of the CW laser with a well-defined vertical polarization and the power of $10 \mathrm{~mW}$. The convex lens with a focal length of $18 \mathrm{~cm}$, was used to focus the laser beam on the sample, the samples were excited at normal incidence geometry for the laser beam. In order to measure transmittance as a function of the sample position, the sample was moved back and forth along the $\mathrm{z}$-axis around the minimum beam waist of the laser during the $\mathrm{z}$-scan measurement. We managed to analyses the distortions of beam wave front associated with distinct effects nonlinear variation of the refractive index, by controlling the diameter of the aperture $(S=0.1-0.3)$. The schematic of the setup for the $\mathrm{z}$-scan experiment, is shown in Fig. 2 [15].

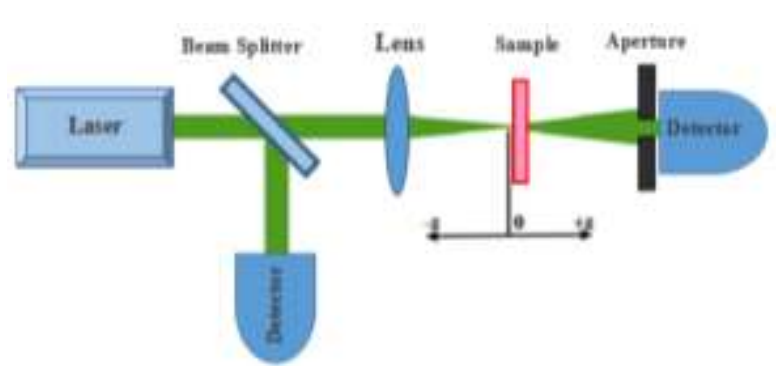

Fig. 2. Schematic diagram of the experimental setup for closed aperture $\mathrm{z}$-scan technique.

\section{Surface Plasmon Polariton (SPP) Excitation}

A high numerical aperture objective lens can be used to excitation surface plasmonpolariton (SPP). In this work, a high numerical aperture objective lens $(10 x, N A=1.25)$ used for SPPs excitation, as shown in Fig. 3(a), objective lens through the oil layer (oilimmersion) is in contact with the sample, and the input laser beam is focused onto the sample by the objective lens. High NA satisfies the dispersion condition between SPPs and incident laser. The propagation constant of the excited SPPs of the Ag NWs is given by

$$
k_{s p}(\omega)=\frac{\omega}{c} \sqrt{\frac{\varepsilon_{1}(\omega) \varepsilon_{2}(\omega)}{\varepsilon_{1}(\omega)+\varepsilon_{2}(\omega)}}
$$

where $\omega$ is angular frequency, $c$ is the light speed in vacuum, and $\varepsilon_{1}(\omega)$ and $\varepsilon_{2}(\omega)$ are the relative permittivity of the Ag NWs and PVP, respectively [16]-[18].

The schematic array of our plasmonic imaging system is shown in Fig. 3(b). According to this figure, the laser beam is divided into two equal parts by a beam splitter. Then, the sample is illuminated by the objective lens, and the reflected light of the sample is received by it.

Finally, the image of the sample will be collected by the lens onto the CCD camera. 


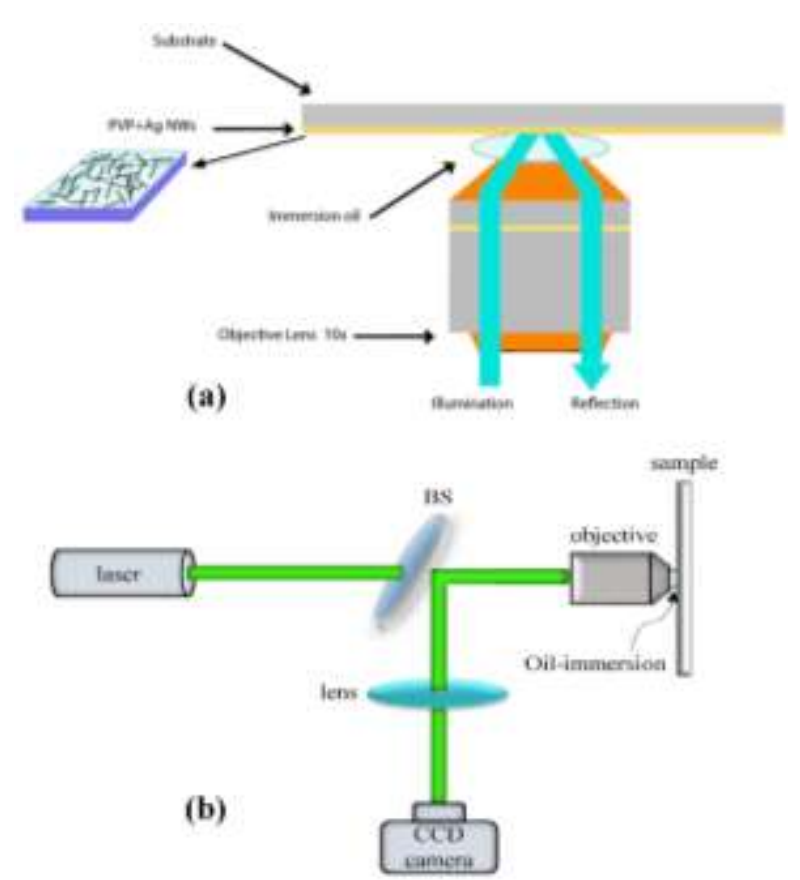

Fig. 3. (a) SPPs excitation by a high NA objective lens, (b) schematic array of the plasmonic imaging system.

\section{III.RESULTS AND DISCUSSION}

The UV-VIS absorption spectra of the samples used in this work are shown in Fig. 4. We can clearly observe the absorption spectrum changes accordingly to their Ag NWs ratio. In addition, the absorption spectrum of this sample indicates that the intensity peak becomes stronger as $\mathrm{Ag}$ NWs quantity increases. Moreover, the absorption spectra of the samples containing three distinct peaks at wavelengths of $285 \mathrm{~nm}$ indicates absorption PVP polymer, as well two peaks at $300 \mathrm{~nm}$ and 330nm indicates absorption Ag NWs.

Measurements of the nonlinear refractive index of samples revealed by using the z-scan technique. The scan started from a distance near the focus until out of focus.

A nonlinear refractive index has been observed, the peak-valley pattern of the normalized transmittance curve configuration indicates the positive sign in which the peak comes after the transmittance valley for all the samples, as are shown in Fig. 5 and the linear absorption coefficient, the difference between $\mathrm{T}$ in peak and valley and $\mathrm{n}_{2}$ are summarized in the Table 1.

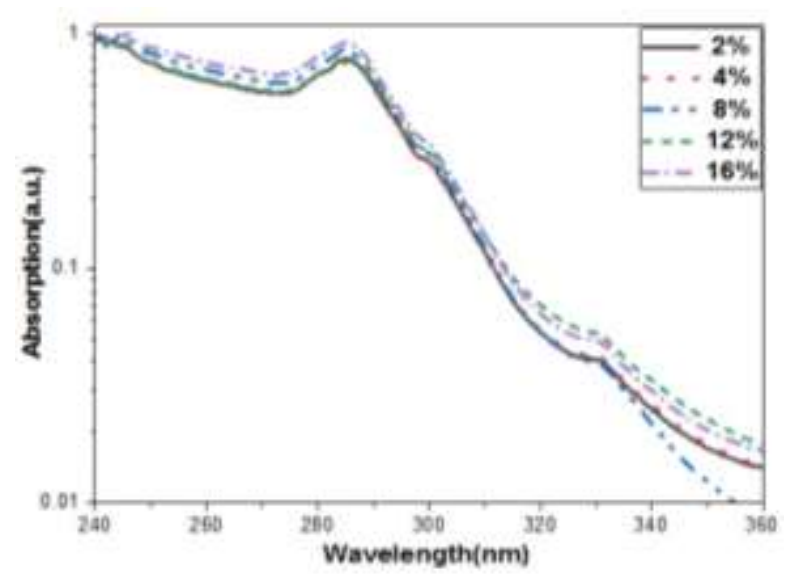

Fig. 4. Absorption spectra of different samples by concentrations set to $2,4,6,8$ and 16 percent.

These parameters show that the nonlinear refractive index of the PVP films is increased when the Ag NWs ratio increases. Results are explained that $\mathrm{n}_{2}$ parameter of the PVP films can be controlled by adding different ratios for Ag NWs to polymer.

Table 1. The linear and nonlinear optical parameters for all the samples

\begin{tabular}{|c|c|c|c|c|}
$\begin{array}{l}\text { Compositio } \\
\text { nal } \\
\text { percentages } \\
\text { of the } \\
\text { samples }\end{array}$ & $\begin{array}{c}\text { Linear } \\
\text { absorption } \\
\text { coefficient } \alpha \\
\left(\mathrm{cm}^{-1}\right)\end{array}$ & $\Delta \mathrm{T}_{\mathrm{P}-\mathrm{V}}$ & $\Delta \emptyset_{0}$ & $\begin{array}{c}\mathrm{n}_{2} \\
\left(\mathrm{~cm}^{2} / \text { watt }\right)\end{array}$ \\
\hline $2 \%$ & 0.24 & 0.0078 & 0.019 & $1.89 \times 10^{-11}$ \\
\hline $4 \%$ & 0.14 & 0.0105 & 0.026 & $2.54 \times 10^{-11}$ \\
\hline $8 \%$ & 0.23 & 0.014 & 0.034 & $3.40 \times 10^{-11}$ \\
\hline $12 \%$ & 0.20 & 0.0258 & 0.064 & $6.27 \times 10^{-11}$ \\
\hline $16 \%$ & 0.28 & 0.0879 & 0.216 & $21.10 \times 10^{-11}$ \\
\hline
\end{tabular}

In the next step, we investigate the plasmonic hot spot of the samples to get the sense about the dependence of the nonlinearity and hot spots.

The hot spot images for our five samples are shown in Fig. 6. One can see the excited SPPs by two different wavelengths, $532 \mathrm{~nm}$ in the left column and $405 \mathrm{~nm}$ in the right column. Figure 6. approves that the blue wavelength $(405 \mathrm{~nm})$ can excite the SPPs better than the green wavelength $(532 \mathrm{~nm})$ that is because we have $\mathrm{Ag} \mathrm{NWs}$ and this material have a good absorption in blue range. In addition, increasing of Ag NWs concentration yield to enhance the hotspots width, because the increasing of SPPs due to increasing in the internal electric field. This fact can be 
approved in Tables 2 and 3, as we list properties of hotspot like hotspot width at $14 \%$ of full intensity and at half width as $50 \%$.

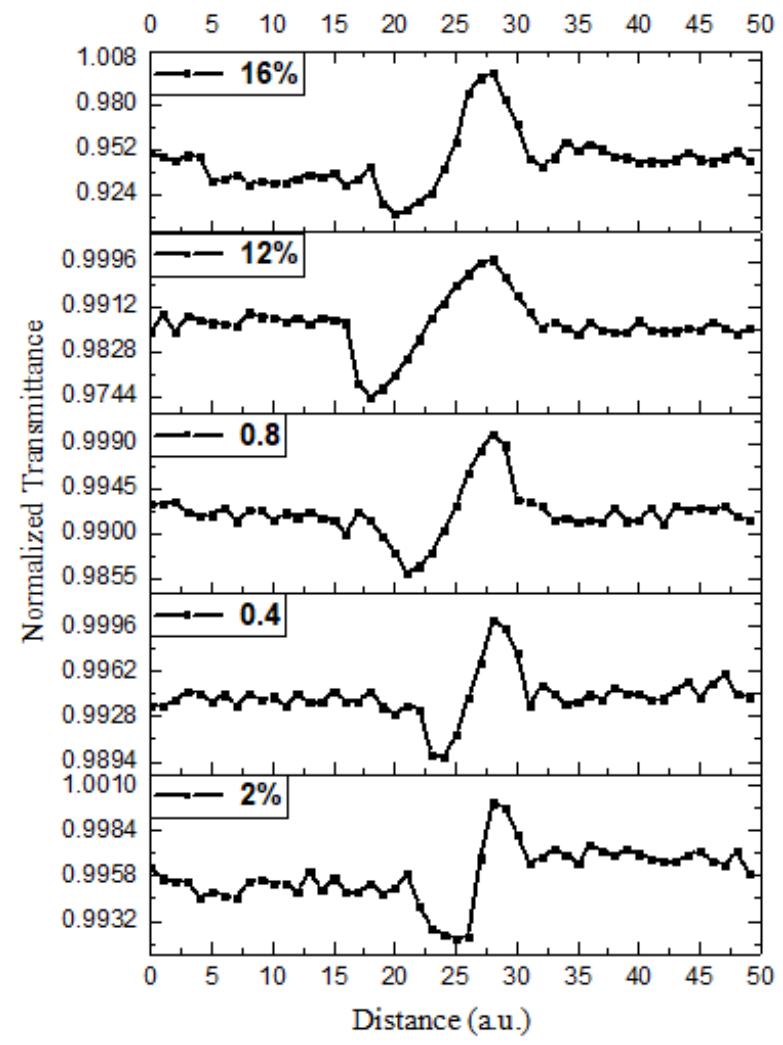

Fig. 5. Transmittance with closed aperture z-scan for all samples.

Accordance with the peak value. In these tables, the width of hotspot in $\mathrm{X}$ direction not equal or close to the $\mathrm{Y}$ direction this is because the polariton of Ag NWs.

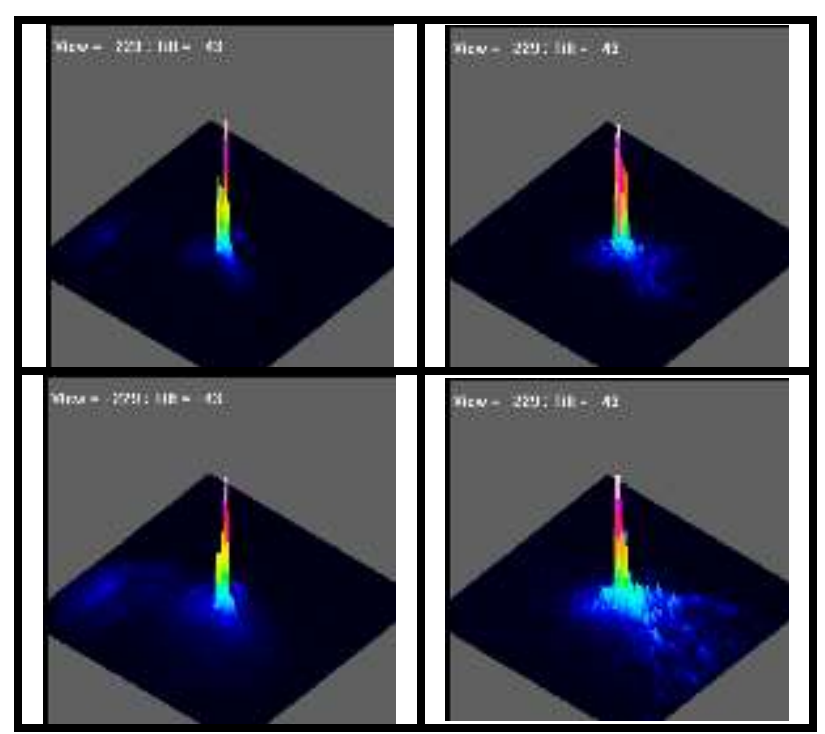

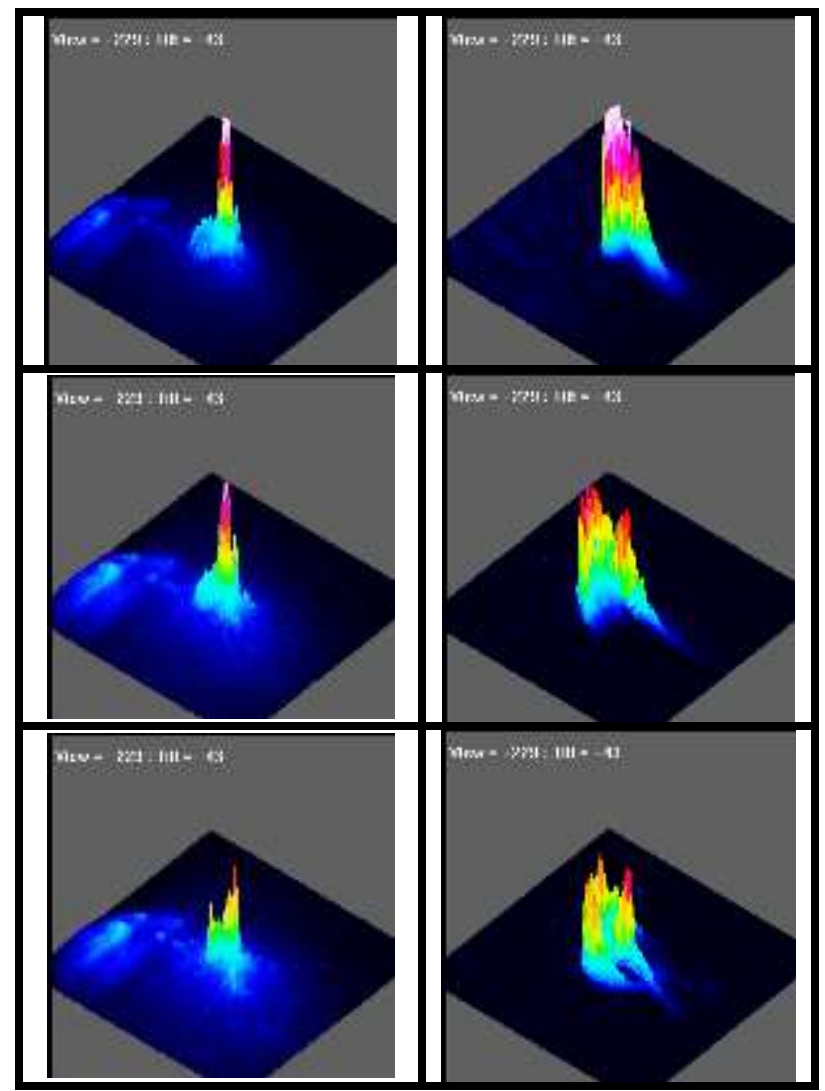

Fig. 6. Hot spot for five different concentrations (from top to bottom) samples, left images for green excitation, right images for blue excitation.

The logic trend can be seen below half intensity of spots in $\mathrm{X}$ and also $\mathrm{Y}$ directions by enhancement in the Ag NWs concentrations. We can note the behavior of peaks values; it almost decreases when the concentration on Ag NWs increasing in our samples that is occurs because increasing in SPPs dispersion. Another fact which appears from this figures is not logic trend in the intensity at $50 \%$ that is logic because non symmetric distribution of NWs in the coating processes.

Table 2. Hotspots properties for five different samples excited by $532 \mathrm{~nm}$

\begin{tabular}{|c|c|c|c|c|c|}
\hline \multirow[t]{2}{*}{ Samples } & \multicolumn{2}{|c|}{$\begin{array}{c}\text { width of } \\
\text { hotspot at } \mathrm{X} \\
\text { direction }(\mu \mathrm{m})\end{array}$} & \multicolumn{2}{|c|}{$\begin{array}{c}\text { width of } \\
\text { hotspot at } \mathrm{Y} \\
\text { direction }(\mu \mathrm{m})\end{array}$} & \multirow{2}{*}{$\begin{array}{c}\text { Peak } \\
\text { value } \\
\%\end{array}$} \\
\hline & $\begin{array}{l}\text { at } \\
14 \%\end{array}$ & $\begin{array}{c}\text { at } \\
50 \%\end{array}$ & $\begin{array}{c}\text { at } \\
14 \%\end{array}$ & $\begin{array}{c}\text { at } \\
50 \%\end{array}$ & \\
\hline Sample 1 & 127.7 & 54.4 & 168 & 99.9 & 92.6 \\
\hline Sample 2 & 166 & 76.6 & 114.7 & 57.1 & 91.8 \\
\hline Sample 3 & 200.3 & 51.5 & 358.6 & 124.2 & 91 \\
\hline Sample 4 & 349.7 & 53 & 424 & 145 & 90 \\
\hline Sample 5 & 403.2 & 199 & 1047 & 228.4 & 64.2 \\
\hline
\end{tabular}


Table 3. Hotspots properties for five different samples excited by $405 \mathrm{~nm}$

\begin{tabular}{|c|c|c|c|c|c|}
\hline \multirow{3}{*}{ Samples } & \multicolumn{2}{|c|}{$\begin{array}{c}\text { width of } \\
\text { hotspot at X } \\
\text { direction } \\
(\mu \mathrm{m})\end{array}$} & \multicolumn{2}{c|}{$\begin{array}{c}\text { width of } \\
\text { hotspot at Y } \\
\text { direction }(\mu \mathrm{m})\end{array}$} & $\begin{array}{c}\text { Peak } \\
\text { value } \\
\end{array}$ \\
\cline { 2 - 5 } & $\begin{array}{c}\mathrm{At} \\
14 \%\end{array}$ & $\begin{array}{c}\mathrm{At} \\
50 \%\end{array}$ & $\begin{array}{c}\mathrm{At} \\
14 \%\end{array}$ & $\begin{array}{c}\mathrm{At} \\
50 \%\end{array}$ & \\
\hline Sample 1 & 140.1 & 93 & 189 & 41.5 & 97.7 \\
\hline Sample 2 & 244.8 & 40.6 & 249.5 & 99.3 & 100 \\
\hline Sample 3 & 260 & 80 & 534 & 207.7 & 100 \\
\hline Sample 4 & 413.7 & 33 & 752 & 615.8 & 77.8 \\
\hline Sample 5 & 405.3 & 334.7 & 590 & 403.1 & 67.9 \\
\hline
\end{tabular}

\section{CONCLUSION}

In summary, the nonlinear responses of $\mathrm{Ag}$ NWs in PVP mixtures are determined. We studied the effect of PVP of the nonlinear refractive index of $\mathrm{Ag} \mathrm{NWs}$, using $\mathrm{Z}$-scan technique. In addition, we used high numerical aperture objective lens to excite the SPPs on Ag NWs. In the closed aperture, a strong variation of $\mathrm{n} 2$ can be observed when the pure Ag NWs were dispersed in PVP in order $10^{-11}$ $\mathrm{cm} 2 /$ watt.

The results that we have from this work proved the peak value of hot spot will be decreases when the concentration of Ag NWs increasing. This decreasing occurs by increment in dispersion of polaritons. Furthermore, the excitation of SPPs by blue laser is better than the excitation by green because the absorbance of Ag NWs near the blue range. Such results suggest that PVP doped with Ag NWs can be a good candidate for such a dielectric medium and it can be useful for gain enhancement applications.

\section{REFERENCES}

[1] R. w. Boyd, Nonlinear Optics in the TwoLevel Approximation, Nonlinear Optics, Academic Press, 1992.

[2] I. Ledoux and J. Zyss, "Nonlinear Organic Molecules and Materials for Optoelectronic Devices," J. Nonlinear Opt. Phys. Mater. Vol. 3, pp. 287-316, 1994.

[3] R. Rodríguez-Oliveros and J.A. Sánchez-Gil, "Gold nanostars as thermoplasmonic nanoparticles for optical heating," Opt. Express, Vol. 20, pp 621-626, 2011.
[4] J. Gu, Y. Yan, Y. Sheng Zhao, and J. Yao, "Controlled Synthesis of Bulk Polymer Nanocomposites with Tunable Second Order Nonlinear Optical Properties," Adv. Mater. Vol. 24, pp. 2249-2253, 2012.

[5] M. Junaidi Yunus, T. Kuwat, Harsojo, and E. Suharyadi, "Chloride ion addition for controlling shapes and properties of silver nanorods capped by polyvinyl alcohol synthesized using polyol method," AIP Conf. Proc, Vol. 1725, pp. 020031 (1-7), 2016.

[6] H. Basri, A. F. Ismail, and M. Aziz, "Polyethersulfone (PES)-silver composite UF membrane: Effect of silver loading and PVP molecular weight on membrane morphology and antibacterial activity," Desalination, Vol. 273, pp. 72-80, 2011.

[7] J.J. Zhu, C.X. Kan, J.G. Wan, M. Han, and G.H. Wang, "High-Yield Synthesis of Uniform Ag Nanowires with High Aspect Ratios by Introducing the Long-Chain PVP in an Improved Polyol Process," J. Nanomaterials, Vol. 2011, pp. 1-7, 2011.

[8] C. Huaman, L. Jhon, I. Urushizaki, and B. Jeyadevan, "Large-Scale $\mathrm{Cu}$ Nanowire Synthesis by PVP-Ethylene Glycol Route," J. Nanomaterials, Vol. 2018, pp. 1-10, 2018.

[9] R. Allu, B. Dipanjan, A. Ravikiran, S. Hamad, S. V. Rao, and G. K. Podagatlapalli, "Broadband femtosecond nonlinear optical properties of silver nanowire films," Opt. Mater. Vol. 96, pp. 109305 (1-7), 2019.

[10]L. Gharibshahi, E. Saion, E. Gharibshahi, A. H. Shaari, and K. A. Matori, "Influence of Poly(vinylpyrrolidone) concentration on properties of silver nanoparticles manufactured by modified thermal treatment method," PLOS ONE, Vol. 12, pp. e0186094 (1-18), 2017.

[11] S. Liu, L. Haitao, H. Zhaohui, F. Minghao, L. Yan-gai, W. Xiaowen, and C. He, "Novel method of ordering silver nanowires for synthesizing flexible films and their conductivity," Mater. Research Express, Vol. 3, pp. 115022 (1-9), 2016.

[12]H. Mbarak, A.K. Kodeary, S.M. Hamidi, E. Mohajarani, and Y. Zaatar, "Control of nonlinear refractive index of AuNPs doped with nematic liquid crystal under external electric field," Optik, Vol. 198, pp. 163299, 2019. 
[13]C. T. Pan, T. L. Yang, C. Chen, S. Ju, I. Wu, Y. Lin, and C. Y. Su, "Investigation of Materials Used in Synthesis for Silver Nanowires and Nanoparticles," Sens. Mater. Vol. 28, pp. 485-492, 2016.

[14] S. Lau, K. Siew, X. Chin, S. T. Tan, F. S. Lim, W. S. Chang, C. Ch. Yap, M. H. Jumali, S. Zakaria, W. Soon, and H. Chin Chia, "Silver nanowires as flexible transparent electrode: Role of PVP chain length," J. Alloys Comp. Vol. 803, pp.165-171, 2019.

[15] A. K. Kodeary and S. M. Hamidi, "Tunable Piezophotonic Effect on Core-Shell Nanoparticles Prepared by Laser Ablation in Liquids under External Voltage," Beilstein J. Nanotechnol. Vol. 2019, pp. 1-11, 2019.

[16]S. F. Haddawi, M. Mirahmadi, H. Mbarak, A. K. Kodeary, M. Ghasemi, and S. M. Hamidi, "Footprint of plexcitonic states in low-power green-blue plasmonic random laser,” Appl. Phys. A, Vol. 125, pp. 843, 2019.

[17]P. Ghosh, G. Han, M. De, C. Kim, and V. Rotello, "Gold nanoparticles in delivery applications," Adv. Drug Deliv. Rev, Vol. 60, pp. 1307-1315, 2008.

[18] J. Choi, Y. Jaemoon, J. Eunji, J-S. Suh, Y.-M. Huh, K. Lee, and S. Haam, "Gold Nanostructures as Photothermal Therapy Agent for Cancer," Curr. Med. Chem. Vol. 11, pp. 953-964, 2011.

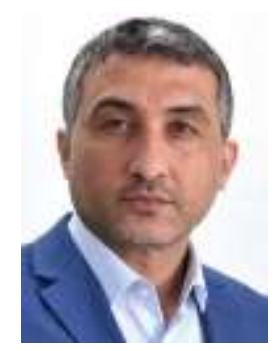

Nizar Shnan received his B.S. degree (2000), M.Sc.degree (2003) in Physics from University of Baghdad, Iraq, and his Ph.D. (2013) in Photonics from University of AlMustansiriyah, Iraq. He then joined to the Magneto-Plasmonic Lab., Laser and Plasma Research Institute, Shahid Beheshti University, Tehran, Iran as a postdoctral fellow since 2019 . He is currently an assistant professor and a group leader at University of Babylon, Iraq, Department of Laser Physics since 2007. His main research interests focus on the fields of laser physics, optical communication, electronic and optoelectronic devices, and nanotechnology.

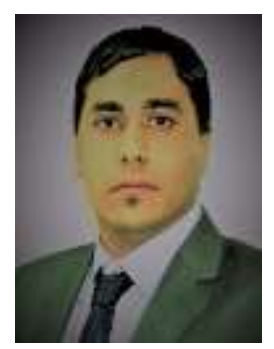

Ahmed Kodeary received his B.S. degree (2006) and M.Sc. degree in laser physics (2012) from College of Science, Babylon University, Hilla, Iraq. He worked as a lecturer in Laser Physics Department, College of Science for Women, Babylon University, Iraq, since 2007 . He is currently a Ph.D. student in the Magneto-Plasmonic Lab., Laser and Plasma Research Institute, Shahid Beheshti University, Tehran, Iran. His research interests include nanotechnology, laser physics, nonlinear optics, magneto-plasmonic, and piezo-electronics nanogenerators.

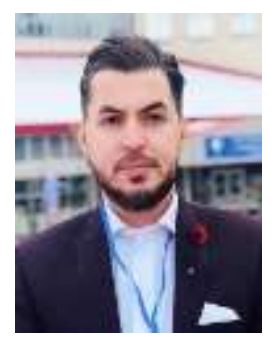

Saddam Haddawi received his B.S. degree in Physics from Babylon University, Iraq, in 2006, M.Sc. degree in laser physics (2013) from Faculty of Mathematics and Physics, University of Szczecin, Poland. He worked as a lecturer in Laser Physics Department, College of Science for Women, Babylon University, Iraq, since 2007. He is currently a Ph.D. student in University of Baghdad, Iraq. His research interests include synthesis of functional nanomaterials, laser physics, nonlinear optics, plasmonic, and random laser. 


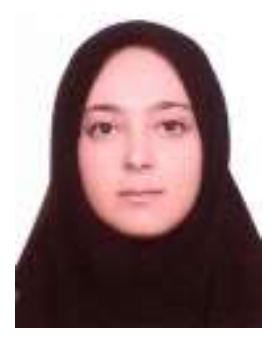

Neda Roostaei received her B.S. degree in Optics \& Laser from Shahid Bahonar University, Kerman, Iran (2014), M.Sc. degree in Photonics from Alzahra University, Tehran, Iran (2016). She is currently a Ph.D. student in the Magneto-Plasmonic Lab., Laser and Plasma Research Institute, Shahid Beheshti University, Tehran, Iran. Her research interests include Metasurfaces, plasmonic Imaging, Microscopy, plasmonics and nanophotonics.

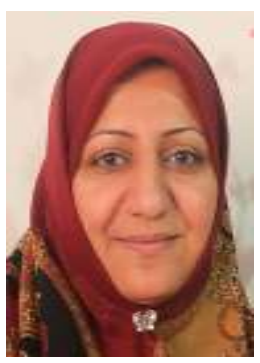

Seyedeh Mehri Hamidi received her Ph.D. degree in photonics from Laser and Plasma Research institute, Shahid Beheshti University, Iran, in 2009. She is currently the director of Magneto-Plasmonic Lab. of Laser and Plasma Research Institute. She works on the research fields of magneto-plasmonic, nanophotonics, neurophotonics, piezotonics, photonic and magnetophotonic crystals, Surface Plasmon Resonance, dielectric and magnetic nanostructures. 
THIS PAGE IS INTENTIONALLY LEFT BLANK. 